\title{
Effect of laparoscopic sleeve gastrectomy on blood sugar and blood pressure
}

Rida J.Al-Basri*, Ali H. Mutar ${ }^{* *}$, Ali M. Tali, Sudad M. Salih***

\begin{abstract}
the
Background: Surgery is one and may be the most effective method to treat obesity. In the last decade, Laparoscopic Sleeve Gastrectomy is perceived to be less invasive, technically simple, less morbid and more popular form of bariatric surgery.

Objectives: This study aims to assess the effect of Laparoscopic Sleeve Gastrectomy on Fasting Blood Glucose Levels and Blood Pressure.

Methods: A prospective controlled study in which 50 obese patients were involved, 36 of patients have hypertension and type 2 diabetes mellitus , 7 patients have type 2 diabetes mellitus only, and 7 patients don't have hypertension or type 2 diabetes. All patients were submitted to Laparoscopic Sleeve Gastrectomy at Al-Kindy Teaching Hospital between October 2014 and October 2016.
\end{abstract}

Results: Forty five of patients were females, while five were males. Mean age was 34 years, mean height $159 \mathrm{~cm}$ mean pre Laparoscopic Sleeve Gastrectomy weight was $121 \mathrm{~kg}$. Mean post- Laparoscopic Sleeve Gastrectomy weight was $82 \mathrm{~kg}$. Mean weight loss outcome at 1 year follow-up is $32.23 \%$ of total body weight. . Preoperative initial mean value of fasting blood glucose was $157.4 \mathrm{mg} / \mathrm{dL}$ and the declining occurred at
12 months after Laparoscopic Sleeve Gastrectomy was $97 \mathrm{mg} / \mathrm{dL}$. The hypertension remission rates 1 year after Laparoscopic Sleeve Gastrectomy ranges up to $54 \%$ of total number of patients and $75 \%$ of those with Hypertension.

Conclusions: Laparoscopic Sleeve Gastrectomy has an effect in improving Fasting Blood Glucose Levels and Blood Pressure.

Key words: Obesity, Laparoscopic Sleeve Gastrectomy Type 2 Diabetes Mellitus, Hypertension .

\section{Corresponding Author:}

Consultant Surgeon, RJ Al-Basri Department of General Surgery, Al-Kindi Teaching Hospital.

Email: redagawad@gmail.com

*Specialist Surgeon Department of General Surgery, Al-Kindi Teaching Hospital.

** Candidate for General Surgery(CABS), Al-Kindi Teaching Center.

*** Specialist Anaesthetist Department of Anaesthesia. Al-Kindi Teaching Hospital

Received at 20/2/2019

Accepted at 25/3/2019

\section{INTRODUCTION}

Overweight and obesity are defined by an excess accumulation of adipose ${ }^{(1)}$.

Body mass index (BMI) is a person's weight in kilograms $(\mathrm{kg})$ divided by his or her height in squared meters. Overweight is a BMI of $25.00-29.99$. Obesity is a BMI of 30 or m Laparoscopic Sleeve Gastrectomy ore for either sex ${ }^{(2)}$.

The increasing prevalence of obesity is associated with the increasing incidence of obesity-related co-morbidities, especially type 2 diabetes mellitus (T2DM), hypertension (HT) and dyslipidemia, all well-documented risk factors for cardiovascular disease (CVD). Bariatric surgery has proven to be the only effective treatment modality with sustained long term effects for the treatment of obesity and its related conditions. The global trends from 2003 to 2011 show a decrease in Roux-en-Y gastric bypass(RYGB) and a marked 
increase in Laparoscopic sleeve castrectomy (LSG). ${ }^{(3)}$.

The gastric sleeve surgery reduces the amount of ghrelin "the hunger hormone", which is produced in the stomach portion that is removed from the body and includes almost the entire gastric fundus . In many obese patients, ghrelin secretion levels are altered and this consequently makes them feel they need to eat more than they actually require. Gastric sleeve surgery patients not only will they eat less because the capacity of the stomach is reduced by approximately $70 \%$ but also will feel more satiety between meals ${ }^{(6)}$.

The removal of most of the fundus and therefore the reduction in parietal cells, in addition to nausea, vomiting and food intolerance experienced by some LSG patients are at high risk for nutritional deficiencies. ${ }^{(7)}$.

The relationship between obesity and diabetes is of such interdependence that the term 'diabesity' has been coined ${ }^{(8)}$. Body mass index has a strong relationship to diabetes and insulin resistance ${ }^{(9)}$.

Resolution of diabetes following bariatric surgery is predominately caused by marked weight loss resulting in improved insulin sensitivity. ${ }^{(10-12)}$.

By measuring Glycosylated Hemoglobin, Type A1C (HbA1c), we are able to get a comprehensive picture of what an average blood sugar have been over a period of weeks to months ${ }^{(13)}$.

Reactive or postprandial hypoglycemia can affect people who have undergone gastric sleeve or any sort of bariatric surgery procedure $^{(14-15)}$.

Hypoglycemia has been ascribed as a late sign of dumping occurring 1-3 hours after meals, and is typically responsive to dietary modification encompassing frequent small, low carbohydrate meals (16). Although restrictive interventions like LSG would be expected to carry a low risk of dumping syndrome (DS), two prospective studies reported that up to $40 \%$ of patients had symptoms suggestive of dumping syndrome 6-12 months after sleeve gastrectomy ${ }^{(17-18)}$.

The relationship between obesity and hypertension is well acknowledged. The hormone leptin which is secreted by fat cells is significantly elevated following weight gain and in obesity, acts in the brain to elevate blood pressure ${ }^{(19)}$. The accumulation of visceral fat and ectopic fat storage in a number of tissues and organs may be important in the cause and consequences of obesity hypertension (20). Multiple pathophysiologic mechanisms have been proposed to be responsible for obesityrelated hypertension HTN with derangements occurring at the level of major organ systems as well as at the molecular level ${ }^{(21)}$.

It has been proposed that the metabolic syndrome of central or android obesity leads to the development of HTN ${ }^{(23)}$.

Some patients may develop significant orthostatic intolerance due to autonomic insufficiency following bariatric surgery ${ }^{(24)}$.

The aim of this study is to show whether LSG can cure T2DM and hypertension in obese patients.

\section{METHODS}

A prospective study which included 50 patients who were submitted to Laparoscopic Sleeve Gastrectomy (LSG) at Al-Kindy Teaching Hospital between October 2014 and October 2015. Patients mean age of 34 (21-54) years with female: male ratio of 9:1 respectively. Participants are obese patients with mean BMI of 47.9 $\mathrm{kg} / \mathrm{m}^{2}$ (range $32.9-63.7 \mathrm{~kg} / \mathrm{m}^{2}$ ) (Obese grade I, class II, class III, and class IV) with comorbidities such as diabetes mellitus type 2 (T2DM), and/or hypertension. 36 of patients have hypertension (HT) and type 2 diabetes mellitus (T2DM), 7 patients have type 2 diabetes mellitus (T2DM) only, and 7 patients don't have HT or T2DM.

Inclusion criteria included:(1)well informed and motivated patients (2) had a BMI 
$>40 \mathrm{~kg} / \mathrm{m}^{2}$, or BMI $\geq 35 \mathrm{~kg} / \mathrm{m}^{2}$ plus at least one serious comorbidity (3) had acceptable risk for bariatric surgery, and (4) had failed previous attempts at nonsurgical weight loss (4). Bariatric surgery in children under 18 years of age remains controversial ${ }^{(5)}$.

Exclusion criteria are (1) complications like hemorrhage, leak, abscess, stricture, nutrient deficiency (2) gastroesophageal reflex disease (3) Mortality patients

Examinations were conducted 1-3 days prior to surgery, with follow-up 12 months after surgery. Routine investigations were performed including complete blood count, renal and liver function tests, thyroid function test, pulmonary function test, virology (hepatitis B, C and HIV), electrocardiogram (ECG), and chest X-ray. Weight, height, BMI and blood pressure were measured. Fasting blood Glucose FBG, HbA1c and Serum Insulin samples were drawn at all visits.

Patient are considered hypertensive when systolic blood pressure is equal to or above $140 \mathrm{~mm} \mathrm{Hg}$ and/or a diastolic blood pressure equal to or above $90 \mathrm{~mm} \mathrm{Hg}$, (World Health Organization, 2015).

If fasting blood sugar $126 \mathrm{mg} / \mathrm{dL}$ (7 $\mathrm{mmol} / \mathrm{L}$ ) or higher on two separate tests, patients have diabetes, (World Health Organization, 2006).

A prophylactic anticoagulant injection (Enoxaparin) 4000 units subcutaneous was given the night before surgery. Antiemetic injection (Ondansetron) IM was given at time of operation.

$\mathrm{P}$-value is calculated, $\mathrm{p}$-value $<0.05$ is statistically significant.

Hypertensive patients are on oral antihypertensive agents. Diabetic patients are on oral anti-hypoglycemic agents.

Operation was performed in supine position and under general anesthesia with the surgeon standing between the legs of the patient in reverse trendelenburg position. During the SG procedure, a narrow gastric tube was constructed along the lesser curve of the stomach, around an intragastric 36French bougie, giving the patients a stomach volume of about $100 \mathrm{ml}$. A long articulating endoscopic linear cutter (echelonflex60) with $60 \mathrm{~mm}$ staple line is used with any ECHELON $^{\mathrm{TM}} 60$ reload, 6 rows. An x-ray contrast study and abdominal ultrasound were performed on the second postoperative day.

After surgery, most patients are in the hospital for 2 to 5 days and can resume their usual physical activities within 4 to 6 weeks after surgery. Medications are given for pain and nausea. Opioid pain medications are usually needed only for a short period following surgery, if at all. Most patients also receive medication to prevent blood clots. Walking helps to prevent blood clots, and after having this surgery, you will be encouraged to get out of bed as soon as possible.

Postoperatively, Patients were recommended to only drink clear fluids for the first 3 days. On days 3-21 the patients follow a liquid diet with two protein rich nutritional supplements. After 3 weeks, the patients are advised to eat mashed food for one week and then gradually to start eating small portions of protein rich food. The patients were instructed to take supplements of multivitamins, long chain omega-3 fatty acids containing vitamin $\mathrm{D}$ and calcium citrate.

Post-operative blood tests are full blood count, fasting blood glucose FBG, HbA1c, serum insulin, urea and electrolytes, ferritin, folate, vitamin B12, adjusted calcium, 25hydroxy vitamin $\mathrm{D}$, parathyroid hormone, zinc and copper.

Post-operative clinical recorded data include weight, height, body mass index BMI and blood pressure were measured.

Blood tests and clinical recorded data are performed at 3 months, 6 months, and 12 months after the operation.

If blood tests indicate low levels of vitamins or minerals, patient may need to take extra supplements, like, complete A-Z 
multivitamin and mineral, calcium + vitamin D3 combined supplement, vitamin B12 injection, and iron supplement.

Data being collected for patients preoperatively and 12 months post-operatively are analyzed in this study.

\section{STATISTICAL DATA ANALYSIS}

Statistical Package for Social Science version 20 (SPSS 20) was used for both data entry and analysis. Chi-square used to test the significance of association for discrete variables. With assumption $(\mathrm{P}$-value $<0.05)$ is statistically significant.

\section{RESULTS}

A total of 50 patients were involved in this study. 36 of patients have hypertension (HT) and type 2 diabetes mellitus (T2DM), 7 patients have type 2 diabetes mellitus (T2DM) only, and 7 patients don't have HT or T2DM. Forty five $(90 \%)$ of the patients were females, and five (10\%) were males with a female: male ratio of 9:1. Mean age was 34 years (range 21-54 years). Mean height $159 \mathrm{~cm}$ (range $153-178 \mathrm{~cm}$ ), Mean pre-LSG weight was $121 \mathrm{~kg}$ (range 94 $182 \mathrm{~kg}$ ), Mean pre-LSG BMI was $47.9 \mathrm{~kg} / \mathrm{m}^{2}$ (range $32.9-63.7 \mathrm{~kg} / \mathrm{m}^{2}$ ) while mean postLSG weight was $82 \mathrm{~kg}$ (range $60-130 \mathrm{~kg}$ ) $(\mathrm{p}$-value $=0.027)$ with mean post-LSG BMI of $32.4 \mathrm{~kg} / \mathrm{m}^{2}$ ( range $\left.21.0-45.5 \mathrm{~kg} / \mathrm{m}^{2}\right)(\mathrm{p}-$ value $=0.010)$. Mean weight loss outcome at 1 year follow-up is $32.23 \%$ of total body weight. (See table 1)

Table 1. Mean weight pre and 1 year post LSG with BMI \%.

\begin{tabular}{|l|l|l|l|l|l|l|l|}
\hline \multicolumn{4}{|c|}{ Mean weight Kg } & \multicolumn{5}{c|}{ Mean BMI } \\
\hline Pre & Post & Change \% & P value & Pre & Post & Change (\%) & P value \\
\hline 121 & 82 & $-32.23 \%$ & 0.027 & 47.9 & 32.4 & $-32.35 \%$ & $<0.016$ \\
\hline
\end{tabular}

Number of obese patients underwent LSG were 50, while number of patients with reduced weight one year after LSG were $47(94 \%)(\mathrm{P}=0.021)$.

A significant declining in fasting blood glucose (FBG) was observed at day 1 postoperative with mean FBG $131 \mathrm{mg} / \mathrm{dL}(\mathrm{P}<0.002)$ compared to the preoperative initial mean value of 157.4 $\mathrm{mg} / \mathrm{dL}$ (range $85-236 \mathrm{mg} / \mathrm{dL}$ ) and the declining occurred at 12 months after LSG $97 \mathrm{mg} / \mathrm{dL}(\mathrm{P}<$ 0.004) (range $81-149 \mathrm{mg} / \mathrm{dL}$ ). See table 2.

Table 2. Mean glucose levels and mean HbA1c\% in T2DM patients Pre and 1 year Post LSG.

\begin{tabular}{|l|l|l|l|l|l|l|l|}
\hline \multicolumn{4}{|c|}{ Mean Glucose level (mg/dL) } & \multicolumn{5}{c|}{ Mean HbA1c (\%) } \\
\hline Pre & Post & P value & Change (\%) & Pre & Post & P value & Change (\%) \\
\hline 157.4 & 97 & $(\mathrm{P}<0.004)$ & $-38.37 \%$ & 9.1 & 6.4 & $(\mathrm{P}<0.001)$ & $-29.67 \%$ \\
\hline
\end{tabular}

HbA1c is reduced in up to $86 \%$ of patients with elevated HbA1c levels, 12

months after LSG, $(\mathrm{P}=0.021)$. (See table 3) 
Table 3. HbA1c levels reduction rates

\begin{tabular}{|l|l|l|l|}
\hline $\begin{array}{l}\text { Group of patients with } \\
\text { elevated HbA1c }\end{array}$ & $\begin{array}{l}\text { Number of patients with } \\
\text { reduced HbA1c levels } \\
\text { after SG }\end{array}$ & Percentage & P value \\
\hline 43 & 37 & $\begin{array}{l}\text { (86\% of those with } \\
\text { elevated HbA1c })\end{array}$ & 0.021 \\
\hline
\end{tabular}

After LSG 2 patients (4\%) experienced symptoms suggestive of dumping syndrome, the results of reactive hypoglycemia rate in after 1 year of follow-up are shown in table 4 . The reactive hypoglycemia rates of SG ranges up to $2 \%$ of LSG patients, and occurred in patients who had T2DM. $(\mathrm{P}=0.250)$

Table 4. Percentage of patients developed reactive hypoglycemia 1 year after LSG.

\begin{tabular}{|l|l|l|l|}
\hline $\begin{array}{l}\text { No. of } \\
\text { patients }\end{array}$ & $\begin{array}{l}\text { No. of patients developed } \\
\text { reactive hypoglycemia 1 year } \\
\text { after LSG }\end{array}$ & Percentage & P value \\
\hline 50 & 1 & $2 \%$ & 0.250 \\
\hline
\end{tabular}

The present study showed important early changes consisting in reductions of mean values of plasma insulin one year after $\mathrm{SG}$ ranges up to $75.43 \%(\mathrm{P}=0.008)$ in 43 obese patients with T2DM.

The hypertension (HT) remission rates after LSG ranges up to 54\% of total number of patients $(\mathrm{P}=0.022)$ and $75 \%$ of those with HT $(\mathrm{P}=0.012)$.

\section{DISCUSSION}

As anticipated, BMI was significantly reduced 12 months postoperatively. Fasting blood glucose and blood pressure were reduced 12 months postoperatively.

Hypertensive obese patients discontinued oral antihypertensive drugs after the remission of hypertension, also patients with T2DM discontinued oral hypoglycemic agents after the remission of T2DM.

The present study showed important early changes consisting in reductions of mean values of plasma insulin after LSG.
After LSG 2 patients (4\%) experienced symptoms suggestive of dumping syndrome, hypoglycemia occurred in 1 patient after 1 year. The consideration of LSG as a pure restrictive procedure need to be further investigated.

In our study the sleeve gastrectomy failure rate was about $6 \%$. Patients with binge eating disorder may continue this disordered eating behavior postoperatively, resulting in surgical failure initially or eventual weight regain.

Mean weight loss was reported in this study. We analyzed the correlation between the mean weight loss and T2DM remission 
rate and the mean weight loss and hypertension remission rate in this study. There was a significant correlation between weight loss and the remission rate of both T2DM and hypertension in the patients managed with laparoscopic sleeve gastrectomy (LSG). K Sarkhosh, DW Birch, X Shi, RS Gill, and S Karmali in their study (The effect of sleeve gastrectomy on hypertension) they searched more than 10 databases from August 2000 to September 2011. Data were combined to calculate overall means across studies. Pre-operative incidence of hypertension was $42 \%$ (range $7 \%$ to $69 \%$ ) where reported. Thirty-three studies were included in the review $(3,997$ participants). They found that Laparoscopic sleeve gastrectomy was associated with resolution of hypertension in $58 \%$ of participants at 12 months of follow-up ${ }^{25}$.

In our study, Laparoscopic sleeve gastrectomy was associated with remission of hypertension in $54 \%$ of participants at 12 months of follow-up ( $\mathrm{P}=0.022)$, which is very close to the study conducted by $\mathrm{K}$ Sarkhosh et al ${ }^{25}$.

Rosenthal R, Li X, Samuel S, Martinez $\mathrm{P}$, Zheng $\mathrm{C}$. in their retrospective study (Effect of sleeve gastrectomy on patients with diabetes mellitus), a review of a prospectively maintained database collected between January 2005 and January 2007. A total of 30 obese patients with T2DM who had undergone laparoscopic sleeve gastrectomy were studied. Of the 30 patients the resolution of T2DM was observed in $63 \%$ at 6 months of follow-up as a result of weight loss after $\mathrm{LSG}^{26}$.

In our study the remission of type 2 diabetes mellitus T2DM was observed in $86 \%$ of diabetic patients at one year of follow-up after LSG $(\mathrm{P}=0.021)$. Our high percent for remission of T2DM was because that our follow-up was for 12 months, while in Rosenthal $\mathrm{R}$ et al research the follow-up was for 6 months.

Tarek Osama Hegazy, Ahmed Abd ElHalem Ewis in their prospective study (Glycemic changes after sleeve gastrectomy in type 2 diabetic morbidly obese patients) conducted on 40 diabetic obese patients (BMI > 35 and a diabetic) at Kasr El-Aini Hospital from July 2011 to May 2013. Patients were managed by laparoscopic sleeve gastrectomy.

They found that there is a significant declining in fasting blood glucose (FBG) levels at 1 day postoperatively (172.5 $\mathrm{mg} / \mathrm{dL})(\mathrm{P}<0.001)$, compared to the basal value $(209 \mathrm{mg} / \mathrm{dL})$. A non-significant declining in FBG occurred at 12th months $(102.9 \mathrm{mg} / \mathrm{dL})(\mathrm{P}=1.0)$ with BMI $(30.2$ $\left.\mathrm{kg} / \mathrm{m}^{2}\right)(\mathrm{P}<0.001)^{27}$.

While in our study a significant declining in fasting blood glucose FBG was observed at day 1 postoperative with mean FBG 131 $\mathrm{mg} / \mathrm{dL} \quad(\mathrm{P}<0.002)$ compared to the preoperative initial mean value of 157.4 $\mathrm{mg} / \mathrm{dL}$ (range $85-236 \mathrm{mg} / \mathrm{dL}$ ) and the declining occurred at 12 months after LSG $97 \mathrm{mg} / \mathrm{dL}(\mathrm{P}<0.004)$ (range 81 - 149 $\mathrm{mg} / \mathrm{dL})$.

\section{CONCLUSION}

In conclusion, based on the data obtained 12 months after surgery, LSG has significant effect on weight loss and appears to be an effective treatment of obesity, probably mediated through low energy intake, the patients' nutritional status did not worsen one year after surgery. There is a significant decrease in fasting blood glucose levels, $\mathrm{HbA1c}$, plasma insulin and blood pressure 12 months after LSG.

\section{RECOMMENDATIONS}

1- Laparoscopic Sleeve gastrectomy is recommended for control of obesityin patients with BMI greater than 40 and control of blood sugar and hypertension.

2- Further study is to be done with a longer follow up period and larger. sample size for further evaluation

\section{REFERENCES}


1. Naser KA, Gruber A, Thomson GA. The emerging pandemic of obesity and diabetes: are we doing enough to prevent a disaster? Int J Clin Pract. 2006;60(9):1093-97.

2. Gallagher D, Heymsfield SB, Heo M, Jebb SA, Murgatroyd PR, Sakamoto Y. Healthy percentage body fat ranges: an approach for developing guidelines based on body mass index. Am J Clin Nutr. 2000;72(3):694-701.

3. Deitel M. Overweight and obesity worldwide now estimated to involve 1.7 billion people. Obes Surg 003;13:329-30.

4. Tsai WS. Inge TH. Burd RS. Bariatric surgery in adolescents: recent national trends in use and in-hospital outcome. Arch Pediatr Adolesc Med. 2007;161:217-21.

5. Velhote MC. Damiani D. Bariatric surgery in adolescents: preliminary 1-year results with a novel technique (Santoro III) Obes Surg. 2008. May 1, [Epub ahead of print].

6. Lee H, Te C, Koshy S, Teixeira JA, Pi-Sunyer FX, Laferrere B. Does ghrelin really matter after bariatric surgery? Surg Obes Relat Dis. 2006;2(5):538-48.

7. Hanne Rosendahl Gjessing, Hans Jørgen Nielsen, Gunnar Mellgren, and Oddrun Anita Gudbrandsen. Energy intake, nutritional status and weight reduction in patients one year after laparoscopic sleeve gastrectomy. 30 July 2013. Available at https://www.ncbi.nlm.nih.gov/pmc/articles/PM C3733076/\#CR5

8. Golay $A^{1}$, Ybarra J. Link between obesity and type 2 diabetes. Service of Therapeutic Education for Diabetes, Obesity and Chronic Diseases, Geneva University Hospital, 24 rue Micheli-du-Crest, Switzerland. alain.golay@hcuge.ch. PMID: 16311223. 2005.07.010.

9. Abdullah S Al-Goblan, Mechanism linking diabetes mellitus and obesity. Diabetes Center, King Fahad Specialist Hospital, Buraidah, Qassim, PO Box 2290, Buraidah 81999, Kingdom of Saudi Arabia, Fax +966 063250 870, imail moc.oohay@nalboga

10. Clements RH. Gonzalez QH. Long CI. Wittert G. Laws HL. Hormonal changes after Roux-en $\mathrm{Y}$ gastric bypass for morbid obesity and the control of type-II diabetes mellitus. Am Surg. 2004;70:1-4

11. Briatore L. Salani B. Andraghetti G. Danovaro C. Sferrazzo E etal Restoration of acute insulin response in T2DM subjects 1 month after biliopancreatic diversion. Obesity (Silver Spring) 2008;16:77-81.
12. Laferrère B. Teixeira J. McGinty J. Tran H. Egger JR etal Effect of weight loss by gastric bypass surgery versus hypocaloric diet on glucose and incretin levels in patients with type 2 diabetes. J Clin Endocrinol Metab. 2008;93:2479-85.

13. Stetler, C., Mueller, B. and Diem, P. 2000. What you always wanted to know about HbA1c. Schweiz Med. Wochenschr, 130 :9931005.

14. Papamargaritis D, le Roux CW, Sioka E, Koukoulis G, Tzovaras G, Zacharoulis D. Changes in gut hormone profile and glucose homeostasis after laparoscopic sleeve gastrectomy. Surg Obes Relat odDis. 2013;9:192-201.

15. Fernando Garcia, MD. Gastric Sleeve and Hypogycemia: Understanding complications. General Surgery Trauma Surgery. 900 W. Magnolia Ave., Suite 200 / Fort Worth, Texas 76104 Get Directions. Primary Phone: (817) 882-1193 Fax: (817) 870-1602. August 26, 2015

16. Tack J, Arts J, Caenepeel P, et al. Pathophysiology, diagnosis and management of postoperative dumping syndrome. Nat Rev Gastroenterol Hepatol. 2009;6:583-90.

17. Tzovaras G., Papamargaritis D., Sioka E., et al. Symptoms suggestive of dumping syndrome after provocation in patients after laparoscopic sleeve

Surgery. 2012;22(1):23-28. gastrectomy. Obesity

18. Papamargaritis D., Koukoulis G., Sioka E., et al. Dumping symptoms and incidence of hypoglycaemia after provocation test at 6 and 12 months after laparoscopic sleeve gastrectomy. Obesity Surgery. 2012;22(10):1600-06. doi: 10.1007/s11695-012-0711-3.

19. Berglund E.D., Vianna C.R., Donato J., Jr., Kim M.H., Chuang J.C., Lee C.E., Lauzon D.A., Lin P., Brule L.J., Scott M.M. Direct leptin action on POMC neurons regulates glucose homeostasis and hepatic insulin sensitivity in mice. J. Clin. Invest. 2012;122:1000-09.

20. Alberti KG, Eckel RH, Grundy SM, Zimmet PZ, Cleeman JI, Donato KA, Fruchart JC, James WP, Loria CM, Smith SC., Jr Harmonizing the metabolic syndrome: A joint interim statement of the International Diabetes Federation Task Force on Epidemiology and Prevention; National Heart, Lung, and Blood Institute; American Heart Association; World Heart Federation; International Atherosclerosis Society; and international association for the 
Study of Obesity. Circulation. 2009;120:164045.

21. Matthew R. Weir M.D. Prophessor of Medicine. Evidence-Based Management of Hypertension $1^{\text {st }}$ edition, Chapter 3; What is the optimal treatment in obesity-related hypertension, ISBN-13: 978-1903378724. ISBN-10: 1903378729.

22. Landsberg L. Pathophysiology of obesityrelated hypertension: role of insulin and the sympathetic nervous system. J Cardiovasc Pharmacol. 1994; 23 (Suppl 1): S1-S8.

23. Scaglione R, Ganguzza A, Parrinello G, et al. Central obesity and hypertension: pathophysiologic role of renal haemodynamics and function. Int $\mathbf{J}$ Obesity Metab Disord. 1995; 19: 403- 09 .

24. Billakanty $\mathrm{SR}^{1}$, Kligman $\mathrm{MD}$, Kanjwal YM, Kosinski DJ, Maly GT, Karabin , Grubb BP. New-onset orthostatic intolerance following bariatric surgery. Division of Cardiovascular Medicine, University of Toledo, Health Science Campus, Toledo, Ohio 43614, USA.
25. K Sarkhosh, DW Birch, X Shi, RS Gill, and S Karmali. The effect of sleeve gastrectomy on hypertension. Center for the Advancement of Minimally Invasive Surgery, Royal Alexandra Hospital, 10240 Kingsway, Edmonton, AB T5H 3 V9, Canada. Available at https://www.ncbi.nlm.nih.gov/pubmed/223509 87

26. Rosenthal R, Li X, Samuel S, Martinez $\mathrm{P}$, Zheng C. Effect of sleeve gastrectomy on patients with diabetes mellitus. Bariatric and Metabolic Institute, Department of Minimally Invasive Surgery, Cleveland Clinic Florida, Weston, Florida 33331, USA. deanh@ccf.org. Available

\section{at} https://www.ncbi.nlm.nih.gov/pubmed/193423 07

27. Tarek Osama Hegazy, Ahmed Abd ElHalem Ewis, Glycemic changes after sleeve gastrectomy in type 2 diabetic morbidly obese patients, Kasr El-Aini Hospital, Kasr El-Aini School of Medicine, Cairo, Egypt. Available at http://scholar.cu.edu.eg/sites/default/files/19 76/files/100001s05th2014-hegazy.pdf 